\title{
Experimental Investigation of Injection Strategies on Low Temperature Combustion Fuelled with Gasoline in a Compression Ignition Engine
}

\author{
Binbin Yang, ${ }^{1,2}$ Mingfa Yao, ${ }^{2}$ Zunqing Zheng, ${ }^{2}$ and Lang Yue ${ }^{2}$ \\ ${ }^{1}$ School of Transportation and Vehicle Engineering, Shandong University of Technology, Zibo 255049, China \\ ${ }^{2}$ State Key Laboratory of Engines, Tianjin University, Tianjin 300072, China \\ Correspondence should be addressed to Mingfa Yao; y_mingfa@tju.edu.cn
}

Received 9 January 2015; Accepted 3 March 2015

Academic Editor: Ming Huo

Copyright (c) 2015 Binbin Yang et al. This is an open access article distributed under the Creative Commons Attribution License, which permits unrestricted use, distribution, and reproduction in any medium, provided the original work is properly cited.

\begin{abstract}
The present study focuses on the experimental investigation on the effect of fuel injection strategies on LTC with gasoline on a single-cylinder CI engine. Firstly, the engine performance and emissions have been explored by sweeping SOI1 and split percentage for the load of $0.9 \mathrm{MPa}$ IMEP at an engine speed of $1500 \mathrm{rpm}$. Then, the double-injection strategy has been tested for load expansion compared with single-injection. The results indicate that, with the fixed CA50, the peak HRR is reduced by advancing SOI1 and increasing split percentage gradually. Higher indicated thermal efficiency, as well as lower MPRR and COV, can be achieved simultaneously with later SOIl and higher split percentage. As split percentage increases, $\mathrm{NO}_{X}$ emission decreases but soot emission increases. CO and THC emissions are increased by earlier SOI1, resulting in a slight decrease in combustion efficiency. Compared with single-injection, the double-injection strategy enables successful expansion of high-efficiency and clean combustion region, with increasing soot, $\mathrm{CO}$, and THC emissions at high loads and slightly declining combustion efficiency and indicated thermal efficiency, however. MPRR and soot emission are considered to be the predominant constraints to the load expansion of gasoline LTC, and they are related to their trade-off relationship.
\end{abstract}

\section{Introduction}

With great concerns about engine emitted pollutant and global warming issues, alternative combustion concepts are drawing increasing attention worldwide. The concepts applied to compression ignition (CI) engines mainly consist of homogeneous charge compression ignition (HCCI) [1], premixed charge compression ignition (PCCI) [2], low temperature combustion (LTC) [3], and so forth. They all share the feature of achieving lower temperature combustion together with a lean mixture distribution by allowing extra time from end of the injection to start of the combustion (SOC), thereby yielding the simultaneous ultra-low nitrogen oxides $\left(\mathrm{NO}_{X}\right)$ and particle matter $(\mathrm{PM})$ emissions, which are greatly challenged in conventional CI engines. Therefore, all these combustion concepts can be labeled under the term of LTC.

LTC concept is generally characterized by long ignition delay, high exhaust gas recirculation (EGR) rate, and premixed charge. With the further research, except the dominating role of chemical kinetics in LTC already been recognized, the importance of fuel and air mixing process has also been realized. However, as the conventional fuel in $\mathrm{CI}$ engines, diesel fuel has cetane number $(\mathrm{CN})$ higher than 40 and poor volatility, which makes its ideal mixing with air before the onset of combustion unachievable at high engine loads even by the combination of a variety of technical means, for example, high pressure injection, cooled EGR, and decreased compression ratio [4]. As a result, the operation range of high-efficiency and clean LTC with diesel is still limited within low and medium loads.

Recently, the fuel properties of LTC have gained great scientific concerns, mainly because fuel properties control the time scales of both chemical kinetics and fuel-air mixing. Thus, it is suggested that a less reactive fuel is preferred for combustion control at high engine loads. In the former studies, mixture of gasoline and diesel termed as dieseline 
by Turner et al. [5] is demonstrated as a promising fuel for simultaneous reduction of $\mathrm{NO}_{X}$ and soot emissions at a lower EGR level, owing to the improved premixture by the better volatility and lower $\mathrm{CN}$. The relevant works have been conducted extensively during the past decade $[5,6]$, but it is challenging to further increase the engine load. Based on the deep insight into fuel properties of LTC, Johansson et al. proposed to inject gasoline directly into cylinder by common-rail system, which is referred to as partially premixed combustion (PPC) concept [7]. Under PPC conditions, autoignition can be made to occur after the fuel and air are well mixed, and soot emission can be reduced. The successful operation of PPC concept with gasoline has been estimated to reach 49$50 \%$ brake efficiency between 1.5 and $2.6 \mathrm{MPa}$ gross indicated mean effective pressure (IMEP) while keeping low emissions [8]. Meanwhile, mixture concentration distribution can be well controlled by adjusting injection strategies, which is favorable for combustion phasing and burning rate control. Furthermore, the high-octane fuel PPC has the ability of reducing the heavy reliance on the EGR usage in diesel LTC, avoiding the consequent fuel economy penalty.

Nevertheless, a full separation between end of the injection and SOC results in unacceptable pressure oscillation which enhances heat transfer and leads to increased specific fuel consumption. Thus, the high pressure rise rate is a great concern for such premixed combustion. In an effort to solve the maximum pressure rise rate (MPRR) issue while maintaining stable combustion, low-octane gasoline has been used to avoid the overmixing of fuel and air [9]. The issue might also be alleviated via applying advanced injection strategies, for example, the double-injection strategy proposed by Kalghatgi et al. [10]. The research identifies that gasoline split injection early in the compression stroke helps reduce MPRR for a given load and enables heat release to occur later with low cyclic variation as compared with single-injection strategy. Because of that, higher IMEP can be reached with lower smoke and $\mathrm{NO}_{X}$; for example, one of the operating points has mean IMEP of $1.595 \mathrm{MPa}$, as well as AVL smoke opacity of $0.33 \%$ and $\mathrm{NO}_{X}$ of $0.58 \mathrm{~g} / \mathrm{kWh}$. The research group from Wisconsin University has conducted some relevant works of comparing the single- and double-injection strategy at A50 (1300 rpm @ 1.3 MPa IMEP) condition [11]. Interestingly, the double-injection strategy produces higher MPRR and $\mathrm{NO}_{X}$ emission as compared to single-injection strategy, which demonstrates the engine performance and emissions are strongly influenced by injection parameters in multi-injection strategy. Ciatti and Subramanian from Argonne National Laboratory have proposed three injection strategies to struggle for meeting the current emission legislation [12]. For the medium and high loads, the partially premixed charge is obtained through an earlier injection and the rest of the fuel is injected around top dead center. As load increases, the first injection has to be well advanced to prepare sufficient premixing charge. The significance of mixture stratification resulting from the overlap of fuel spray and followed combustion in controlling combustion rate has been recognized by Yang et al. [13].

Based on the analysis of the existing problems, the authors intend to explore the effect of fuelling strategies on LTC with
TABLE 1: Engine and injector specifications.

\begin{tabular}{lc}
\hline Bore $(\mathrm{mm})$ & 105 \\
Stroke $(\mathrm{mm})$ & 125 \\
Connecting rod length $(\mathrm{mm})$ & 210 \\
Squish height $(\mathrm{mm})$ & 0.85 \\
Displacement $(\mathrm{L})$ & 1.08 \\
Compression ratio & $16: 1$ \\
Swirl ratio & 1.5 \\
IVO $\left({ }^{\circ} \mathrm{CA}\right.$ ATDC $)$ & -377 \\
IVC $\left({ }^{\circ} \mathrm{CA}\right.$ ATDC $)$ & -133 \\
EVO $\left({ }^{\circ} \mathrm{CA}\right.$ ATDC $)$ & 125 \\
EVC $\left({ }^{\circ} \mathrm{CA}\right.$ ATDC) & -342 \\
\hline
\end{tabular}

93 research octane number (RON) gasoline. The study is driven in two steps. Firstly, a sweeping of start of the first injection (SOI1) and split percentage is experimented in detail to investigate the effect of these two factors on combustion and emission characteristics, as well as to seek for the key limiting factors of operation range expansion. Secondly, the double-injection strategy is tested at high load condition for load expansion, with a baseline experiment with singleinjection. Therefore, the current research will be served as a theoretical evidence for the operation range expansion of high-efficiency and clean combustion in CI engines.

\section{Experimental Apparatus}

2.1. Engine. The experiments were all performed on a modified six-cylinder CI engine. The test cylinder with a displacement of $1.08 \mathrm{~L}$ was separated from other cylinders to avoid multicylinder interference and was equipped with independently adjustable intake/exhaust, exhaust gas recirculation (EGR), and common-rail injection system while other engine components remain intact. The engine specifications are listed in Table 1 . The compression ratio was reduced from original 17.5 to 16 for prolonging ignition delay. Fresh air was externally compressed by an auxiliary compressor to simulate the boosted condition, whose pressure was adjusted by a by-pass valve close to the compressor outlet. Both the EGR valve and the back pressure valve were applied to control the amount of exhaust gas flow into the intake pipe and consequently the EGR rate. The schematic diagram of the engine setup is illustrated in Figure 1.

2.2. Instrumentation. In-cylinder pressure was measured with a pressure transducer (Kistler 6125A) in conjunction with a charge amplifier (Kistler 5011). The shaft encoder (Kistler 2614A4) had a resolution of $0.5^{\circ}$ crank angle (CA). Combustion parameters discussed in this paper were calculated from averages of 100 consecutive cycles of cylinder pressure data. Both heat release rate (HRR) and MPRR were calculated by a combustion analysis software package from the averaged cylinder pressure.

The test cylinder was equipped with a second generation prototype common-rail system from Bosch, which is the same as the one on the original engine. The nozzle had an 


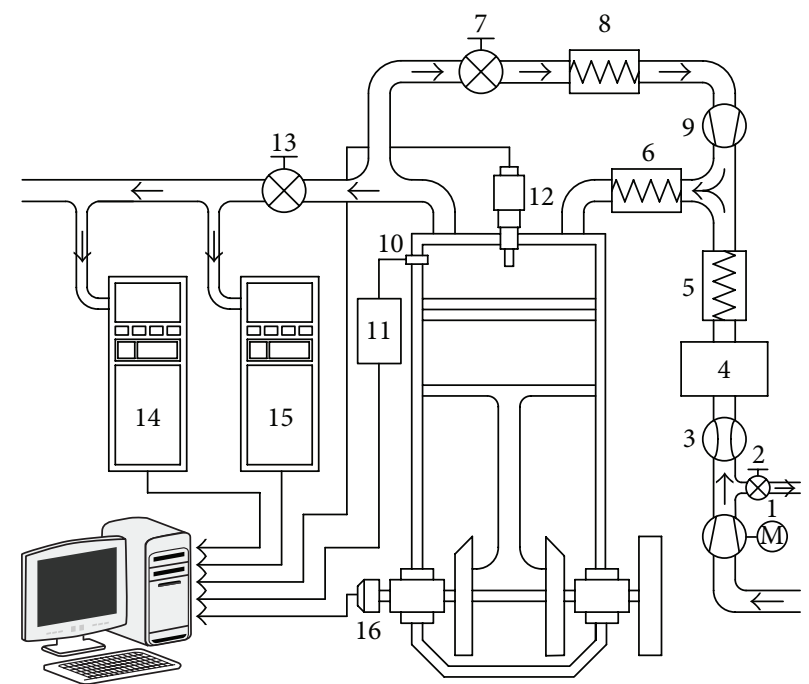
(1) Compressor
(9) One-way valve
(2) By-pass valve
(10) Pressure transducer
(3) Air flow meter
(11) Charge amplifier
(4) Surge tank
(12) Direct injector
(5) Inlet heater
(13) Back pressure valve
(6) Inlet cooler
(14) Exhaust analyzer
(7) EGR valve
(15) Smoke meter
(8) Intercooler
(16) Encoder

FIGURE 1: Schematic of experimental setup.

umbrella angle of $150^{\circ}$ and 8 orifices, whose diameter was $0.15 \mathrm{~mm}$. The ECU for controlling the direct injection system was coordinated by software on a PC. The arrangement enabled flexible settings of common-rail pressure, injection timing, injection quantity, and multi-injection strategies. The fuel flow rate was measured by a fuel consumption meter (AVL 733S) with a gravity scale, and each operating point was sampled for at least 3 minutes.

The concentrations of gaseous emissions, for example, $\mathrm{NO}_{X}$, total hydrocarbon (THC), carbon monoxide (CO), and carbon dioxide $\left(\mathrm{CO}_{2}\right)$, were measured using an exhaust analyzer (Horiba MEXA-7100DEGR), which measures $\mathrm{NO}_{X}$ by the chemiluminescent method, THC by the flame ionization method, and $\mathrm{CO}$ and $\mathrm{CO}_{2}$ by the nondispersive infrared method. The EGR rate was determined via calculating the ratio of intake $\mathrm{CO}_{2}$ to exhaust $\mathrm{CO}_{2}$ concentration, as shown in (1). Consider

$$
\mathrm{EGR}=\frac{\left[\mathrm{CO}_{2}\right]_{\text {intake }}}{\left[\mathrm{CO}_{2}\right]_{\text {exhaust }}} \cdot 100 \% .
$$

A filter smoke meter (AVL 415S) was utilized to measure soot levels in terms of filter smoke number (FSN) and changed into mass by the empirical formula provided by the instrument manual as follows:

$$
\text { soot }=\frac{5.32}{0.405} \times \mathrm{FSN} \times e^{0.3062 \times \mathrm{FSN}} \times 0.001 \times \frac{\left(m_{\text {air }}+m_{\text {fuel }}\right)}{1.2929},
$$

where $m_{\text {air }}$ and $m_{\text {fuel }}$ are the intake air flow and fuel consumption rate, respectively, $\mathrm{kg} / \mathrm{h}$.
During the combustion process, not all the chemical energy of fuel has been released. The analysis of the energy utilization that is represented by the combustion efficiency, namely, the fraction that is burned compared to that which is supplied, is calculated using the following [14]:

$$
\eta_{\text {comp }}=\left(1-\frac{\sum_{i=1}^{n} x_{i} Q_{\mathrm{LHV} i}}{Q_{\mathrm{LHVfuel}}}\right) \cdot 100 \%,
$$

where $x_{i}$ and $Q_{\mathrm{LHV} i}$ represent the mass fractions and lower heating values (LHV) of $\mathrm{HC}, \mathrm{CO}$, and hydrogen $\left(\mathrm{H}_{2}\right)$, respectively. For this study, $Q_{\mathrm{LHVHC}}$ has been treated equal to $Q_{\text {LHVfuel }}$.

Combustion stability was expressed by the coefficient of variability (COV) of IMEP, and a value of $5 \%$ was thought to be an acceptable limit for this type of engine. The COV of IMEP was defined by the following:

$$
\mathrm{COV}_{\text {IMEP }}=\frac{1}{\mathrm{IMEP}_{\text {mean }}} \sqrt{\frac{\sum_{i=1}^{N}\left(\mathrm{IMEP}_{i}-\mathrm{IMEP}_{\text {mean }}\right)^{2}}{N-1}} .
$$

2.3. Fuel. Commercially available $93 \mathrm{RON}$ gasoline was used for all engine tests. Since the high pressure pump and injector were originally designed to operate with diesel fuel, a lubricity agent (Afton H4140 [15]) of $1000 \mathrm{ppm}$ was added to gasoline fuel to avoid failure of the common-rail injection system. The physical and chemical properties of H4140 lubricity agent were listed in Table 2. 
TABLE 2: Physical and chemical properties of H4140 lubricity agent.

\begin{tabular}{lc}
\hline Physical form & Liquid \\
Color & Amber (shallow) \\
Density $\left(\mathrm{kg} / \mathrm{m}^{3}\right)$ & 0.91 \\
Solubility & Insoluble in cold water only \\
Viscosity $\left(\mathrm{cSt} @ 40^{\circ} \mathrm{C}\right)$ & 17 \\
Flash point $\left({ }^{\circ} \mathrm{C}\right)$ & 100 (closed cup) \\
\hline
\end{tabular}

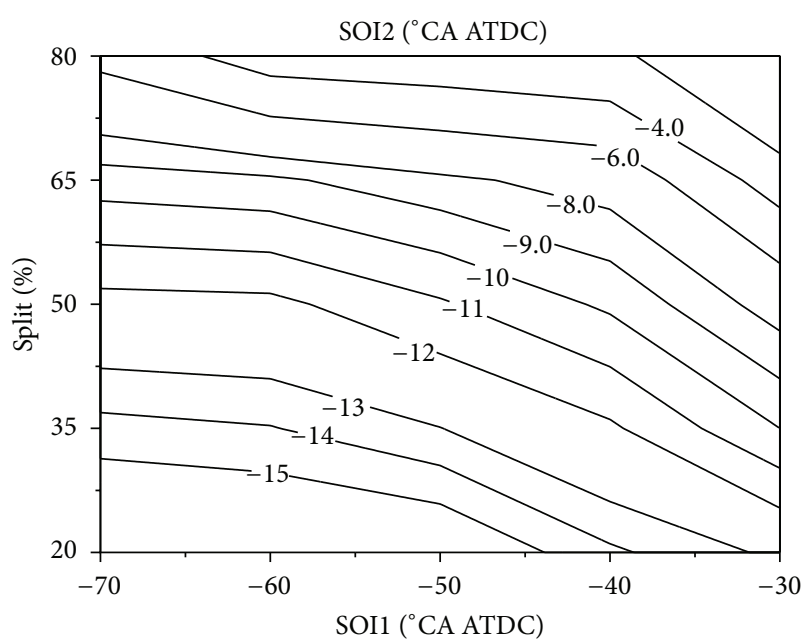

FIGURE 2: SOI2 as a function of SOI1 and split percentage; CA50 set at $10^{\circ} \mathrm{CA}$ ATDC.

\section{Results}

3.1. SOI1 and Split Percentage Sweeping. The major parameters affecting gasoline autoignition considered herein include SOI1 and split percentage. Thus, a sweep in SOI1 and split percentage had firstly been conducted to seek for optimized engine performance and emissions. In this section, the experiments were carried out for the load of $0.9 \mathrm{MPa}$ IMEP (fuelling rate of $50 \mathrm{mg} /$ cycle) at an engine speed of $1500 \mathrm{rpm}$. SOI1 was altered from -30 to $-70^{\circ} \mathrm{CA}$ after top dead center (ATDC) with an interval of $15^{\circ} \mathrm{CA}$ and fuel split percentage from $20 \%$ to $80 \%$ in $10 \%$ intervals, where the remaining fuel was injected in the following injection event. Intake pressure and temperature were raised sufficiently to $220 \mathrm{kPa}$ abs. and $323 \mathrm{~K}$, respectively, for stable combustion. A baseline EGR level of $45 \%$ was used to avoid combustion reactions during the early stage of the compression stroke. Since the cone angle of the injector is as large as $150^{\circ}$, an appropriately lower injection pressure of $40 \mathrm{MPa}$ was applied to reduce spray penetration, avoiding fuel wall-impingement and entering into the crevice volume. During the SOI1 and split percentage sweeping, the combustion phase of $50 \%$ accumulative heat release (CA50) was maintained at $10^{\circ} \mathrm{CA}$ ATDC, for the efficient combustion coupled with acceptable pressure rise rate. Since EGR rate was kept constant during the experiments, CA50 was mainly controlled by start of the second injection (SOI2).

The contour plot in Figure 2 clearly shows the SOI2 as a function of SOI1 and split percentage to keep CA50 fixed.

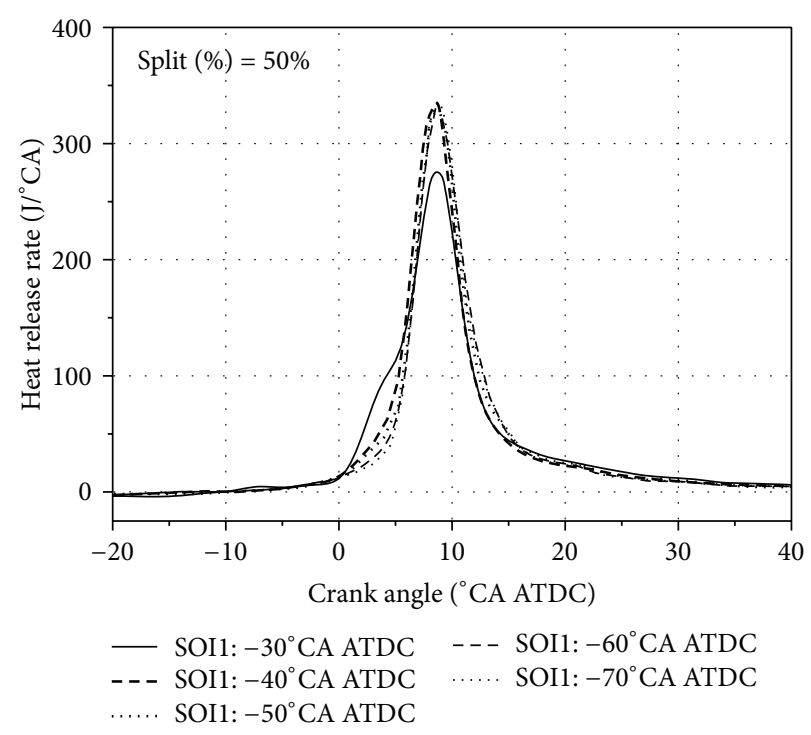

FIGURE 3: Heat release profile as a function of SOI1; split percentage set at $50 \%$.

When SOI1 is advanced, the split fuel and air mixture get even leaner locally and its reactivity is weakened as a consequence, so SOI2 has to be put forward. With the increase of fuel amount in the first injection, the richer premixed charge with enhanced reaction activity has shown the potential to advance the combustion process, so SOI2 has to be delayed for the fixed CA50. It can therefore be concluded that SOI2 should be put forward along with the earlier SOI1 and lower split percentage and retarded closer to TDC otherwise.

Figure 3 presents the effect of SOI1 on heat release profiles while the split percentage is kept at 50\%. In the multiinjection strategy in PCCI concept fuelled with diesel, the pilot fuel with good autoignition property generally occurs to combustion during the compression stroke, forming the heat release process of pilot fuel, which reduces the ignition delay and premixed combustion of the main injection, resulting in lower PRR and noise but higher soot level and fuel economy deterioration. Thus, on an energy basis, the pilot fuel is always kept to less than $25 \%$ of the total fuel [16]. Based on the points discussed above, for the double-injection strategy in gasoline LTC, large amount of EGR is necessary to prevent premature autoignition of the split fuel, and no obvious heat release process is observed before the total fuel is injected into cylinder as a consequence. The following injection event forms a significant stratification of the gasoline vapor and ignites the premixed charge by the split fuel and air mixing, so a single-peak heat release is observed. With SOI1 fixed at $-30^{\circ} \mathrm{CA}$ ATDC, the combustion reaction occurs at an earlier stage, which leads to a slight decrease in peak HRR, as well as a longer combustion duration. The advancement of SOI1 renders better mixing and produces a more uniform mixture of the split fuel and air, whereas the heat release profiles are almost unchanged, which suggests that the effect of mixing time scale on premixed charge is weakened after a period of sufficient mixing. 


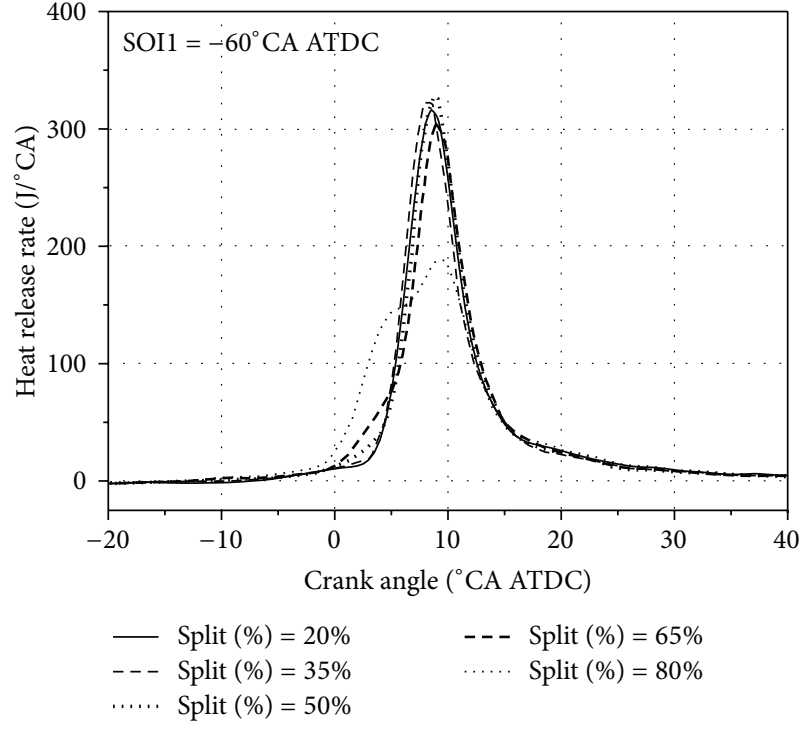

FIGURE 4: Heat release profile as a function of split percentage; SOI1 set at $-60^{\circ} \mathrm{CA}$ ATDC.

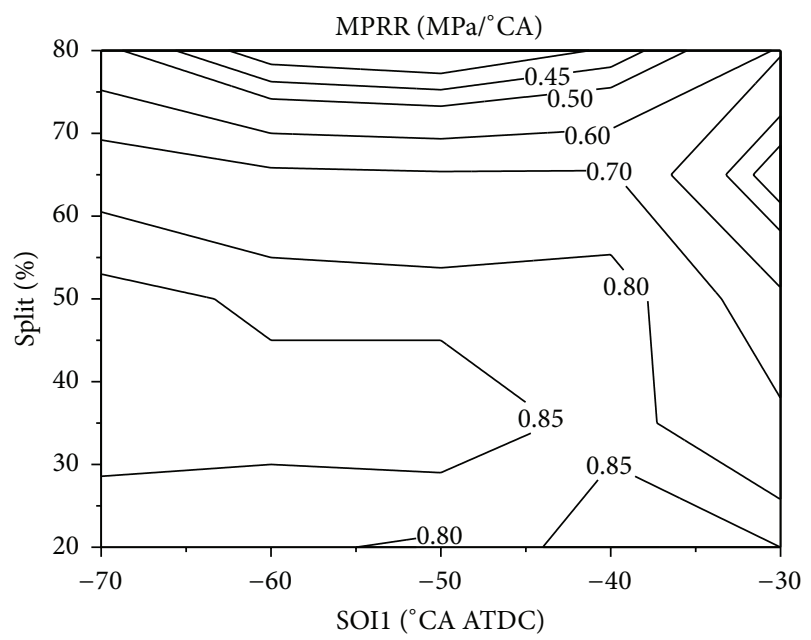

FIGURE 5: MPRR as a function of SOI1 and split percentage.

Figure 4 compares the heat release profiles of various split percentages with SOI1 fixed at $-60^{\circ} \mathrm{CA}$ ATDC. A singlepeak heat release process is observed and remains unaffected with the split percentage ranged from $20 \%$ to $50 \%$ for the reaction of the lean mixture from split fuel suppressed by EGR. As split percentage reaches $65 \%$, the equivalence ratio of the premixed charge is up to 0.3 , which is so reactive that some of the premixed charge occurs to be compressed-ignited before the main combustion process has happened; thereby significant changes are emerging in the heat release profiles. As the fuel split percentage is further increased to $80 \%$, SOC is put forward obviously and a prominent double-peak heat release is noticed, while the equivalence ratio of premixed charge arrives at 0.37 , so a smooth combustion process is achieved consequently.

MPRR for various SOI1s and split percentages are given in Figure 5. Under the single-injection case, fuel and air are

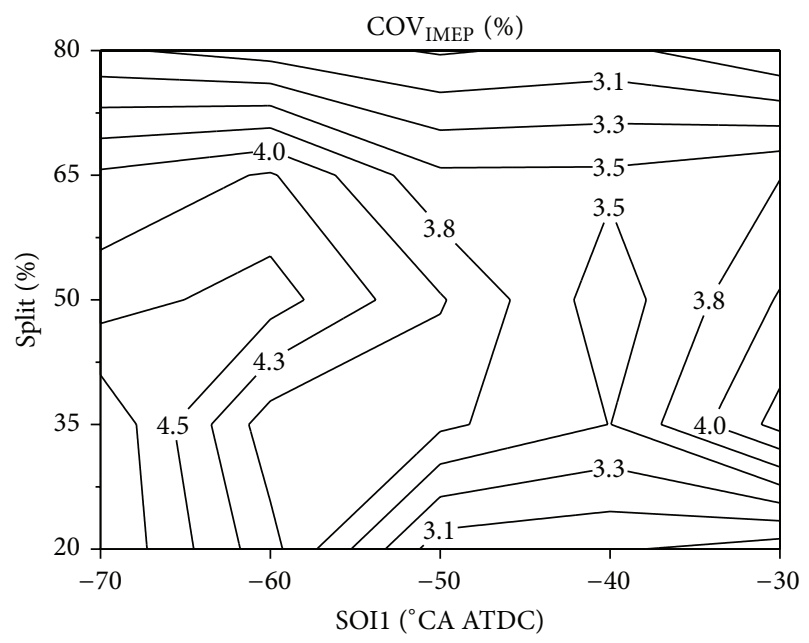

FIGURE 6: $\mathrm{COV}_{\text {IMEP }}$ as a function of SOI1 and split percentage.

well premixed prior to combustion, whereas there is less time interval between end of the second injection event and SOC with double-injection strategy, resulting in mixture stratification. For this reason, the burning rate is greatly alleviated and instantaneous HRR is reduced by the partial overlap of the second injection and combustion. So it is figured out that the region with MPRR below the threshold value of engine knock is pretty broad. Moreover, the increase in split percentage helps improve the fuel stratification. However, the earliness of the first injection provides more time interval for uniform mixing of fuel with air, which is supposed to play a more important role in MPRR as compared to SOI1. Nevertheless, the mixture stratification may also be weakened by excessively low fuel quantity in the second injection; namely, the split fuel accounts for most of the total fuel, resulting in higher MPRR as well.

The influence of SOI1 and split percentage on coefficient of variation of IMEP $\left(\mathrm{COV}_{\text {IMEP }}\right)$ is presented in Figure 6. Compared with single-injection strategy, the combustion stability of the double-injection strategy, indicated by $\mathrm{COV}_{\text {IMEP }}$, declines apparently in terms of the lean mixture caused by the first injection but still within the stable combustion range. Clearly, the lower $\mathrm{COV}_{\text {IMEP }}$ is observed in the regions with higher split percentage and the combination of lower split percentage and later SOIl, which can be attributed to the following reasons: as split percentage exceeds $65 \%$, the equivalence ratio of the premixed charge is sufficient to initiate combustion reaction before the following injection event as mentioned previously; $\mathrm{COV}_{\text {IMEP }}$ becomes less sensitive to SOI1. On the other hand, with split percentage less than $65 \%$, the ignition delay period for the split fuel is so long that the lean mixture is more likely to be disturbed by the in-cylinder airflow with advanced SOIl, thereby increasing cycle-to-cycle variations. The maximum $\mathrm{COV}_{\text {IMEP }}$ appears at the regions with earlier SOI1 and lower split percentage, which delivers superior MPRR level accordingly. Therefore, from the view of combustion control, applying higher split percentage has the capability of achieving simultaneously 


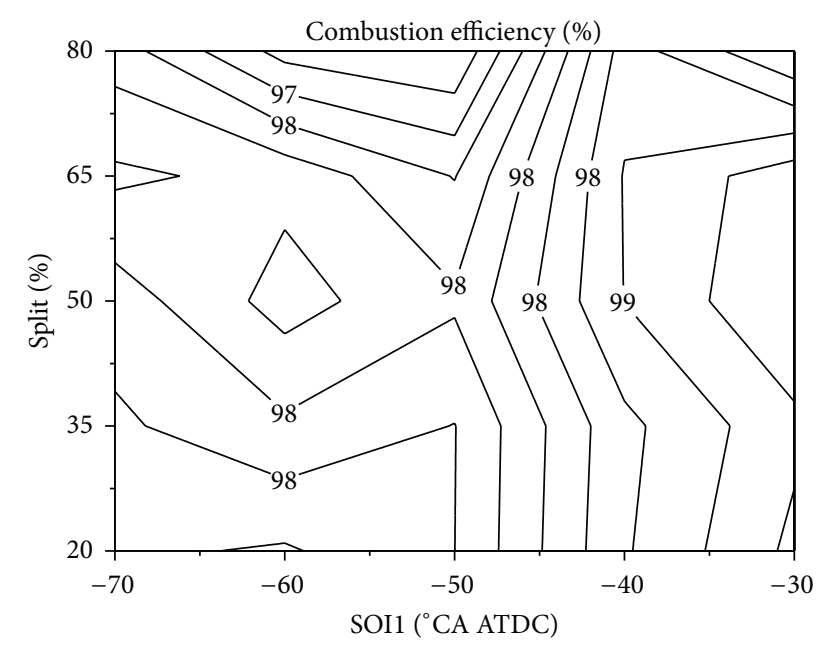

FIGURE 7: Combustion efficiency as a function of SOI1 and split percentage.

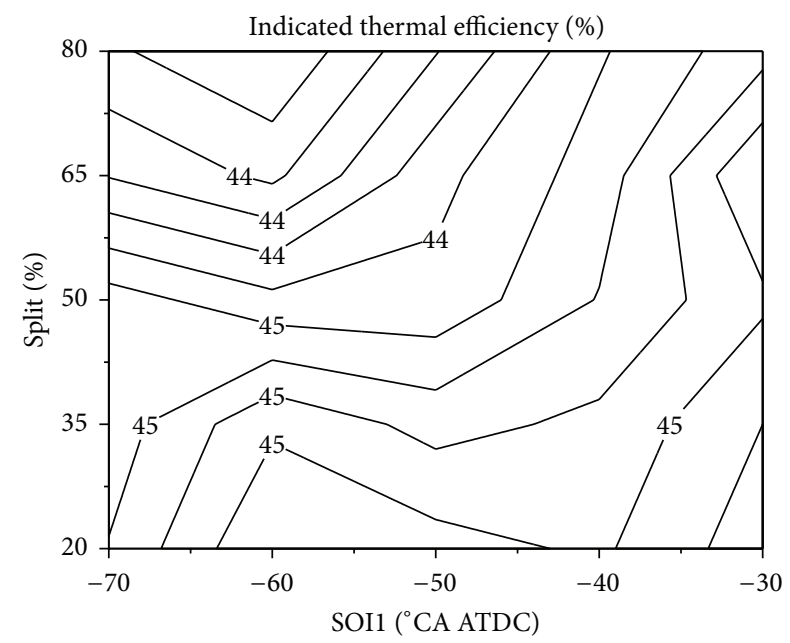

FIGURE 8: Indicated thermal efficiency as a function of SOI1 and split percentage.

lower MPRR and $\mathrm{COV}_{\text {IMEP }}$, which are the indications of the successful operation range expansion of gasoline LTC.

Figure 7 shows the effects of SOI1 and split percentage on combustion efficiency. Overall, the flame quenching in lean premixed charge resulting from advancing SOI1 usually elevates the level of incomplete combustion products to a certain degree, which typically leads to a slight decrease in combustion efficiency. In addition, with the increase of split percentage, the combustion efficiency is reduced further. The detailed relationship between injection parameters and emissions will be discussed in the next section. Owing to the fixed CA50, approximately the same indicated thermal efficiencies under the operation condition are attained, basically between $44 \%$ and $45 \%$, while suffering a little from the lower combustion efficiency in the region with earlier SOI1 and higher split percentage, as shown in Figure 8.
The normalized indicated specific $\mathrm{NO}_{X}$, soot, $\mathrm{CO}$, and THC emissions for various SOIl and split percentage combinations using double-injection are given in Figures 9(a), 9(b), 9(c), and 9(d), respectively. From Figure 9(a), generally more fuel in the first injection means less $\mathrm{NO}_{X}$ emission, so it is clear that the regions with $\mathrm{NO}_{X}$ emission below $0.4 \mathrm{~g} / \mathrm{kWh}$ are fairly board under the test condition. Based on the previous analysis, the reduction of $\mathrm{NO}_{X}$ is mainly due to the locally lower combustion temperature of the lean mixture resulting from the first fuel injection. On the other hand, SOI1 has a relatively small impact on $\mathrm{NO}_{X}$ emission, which exactly corresponds to the previous HRR results. Therefore, the amount of the first injection plays a key role in subduing $\mathrm{NO}_{X}$ emission.

As seen in Figure 9(b), with the advancement of the first injection, soot emission declines gradually due to the enhanced premixing of the split fuel with air, while an increase tendency is observed with more fuel in the first injection. This is mainly because the earliness of SOI1 leads to serious fuel wall-impingement, and the fuel may stick to the engine parts, for example, cylinder wall and piston head, forming an oil film, where more particulates are emitted from the combustion with extremely high equivalence ratio. Meanwhile, in order to keep CA50 fixed, SOI2 is closer to TDC with higher fuel split percentage, thereby mixing period of the second injection is not sufficient; thus the increased diffusion combustion delivers a higher local equivalence ratio, which also leads to soot decortication. Therefore, in order to obtain ideal soot level, the fuelling strategy with the combination of earlier SOI1 and lower split percentage should be employed. Nevertheless, considering the previous results, the regions emitting lower soot emission exactly correspond to those generating higher MPRR and $\mathrm{COV}_{\text {IMEP }}$. Therefore, it is stated that the in-cylinder charge stratification to some extent is necessary for alleviating burning rate, while there could be a price to pay in terms of soot emission. Namely, there exists a trade-off relationship between MPRR and soot with double-injection strategy in the load expansion of gasoline LTC.

As pointed out in Figure 9(c), the relationship between SOI1 and CO emission is dramatically different divided by SOI1 of $-50^{\circ} \mathrm{CA}$ ATDC. If SOI1 is located after $-50^{\circ} \mathrm{CA}$ ATDC, the split fuel undergoes longer ignition delay period prior to SOC with SOI1 advancing, so the local mixture gets even leaner, resulting in lower combustion temperature that proved to be an obstacle for the convention of $\mathrm{CO}$ to $\mathrm{CO}_{2}$. Therefore, $\mathrm{CO}$ emission is strongly influenced by SOI1 but largely unaffected by split percentage. On the other hand, the phenomena become much more complicated. With SOI1 advanced ahead of $-50^{\circ} \mathrm{CA}$ ATDC, the minimum value of $\mathrm{CO}$ emission is obtained with the split percentage of about $50 \%$, while $\mathrm{CO}$ emission is increased whether the split percentage is higher or lower. As split percentage exceeds $50 \%$, the locally leaner mixture cannot generate sufficient temperature for the oxidation of CO. Besides, the SOI2 has to be put forward to keep CA50 fixed as a result of the low split percentage, which also decreases the local equivalence ratio. These two factors combined together result in the special distribution of $\mathrm{CO}$ emission. 


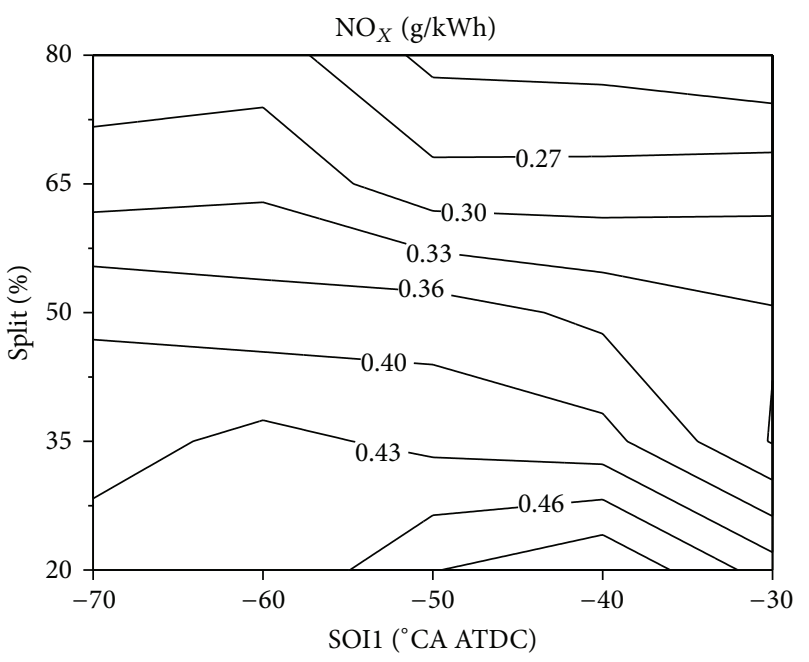

(a) $\mathrm{NO}_{X}$

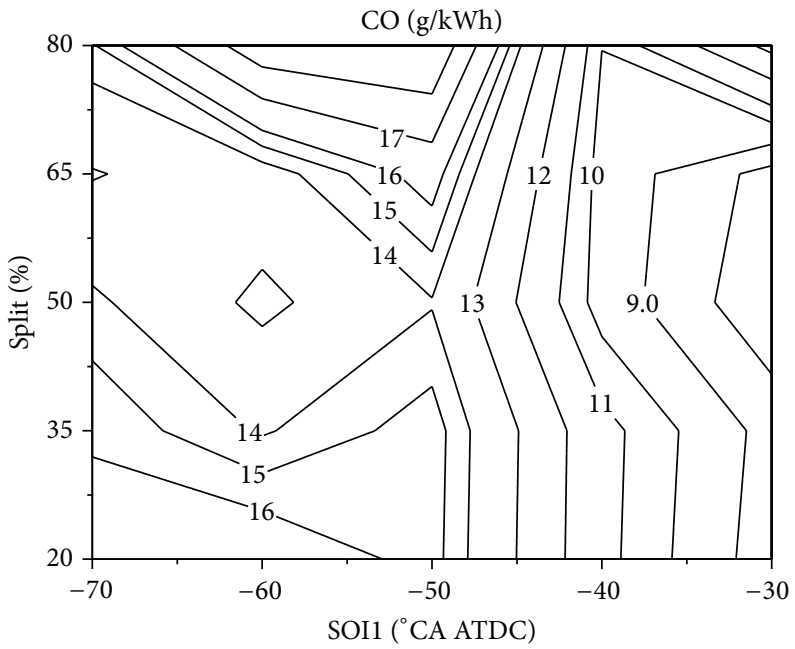

(c) $\mathrm{CO}$

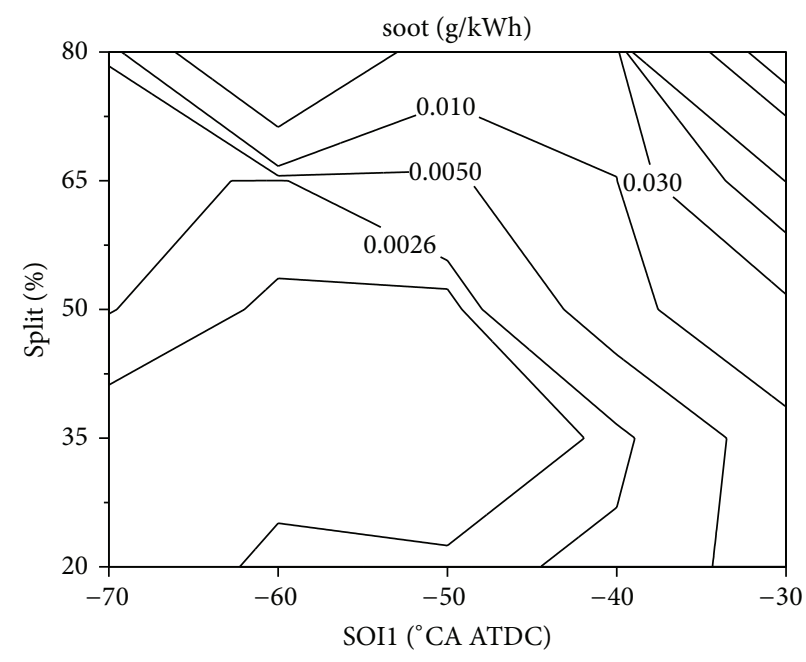

(b) soot

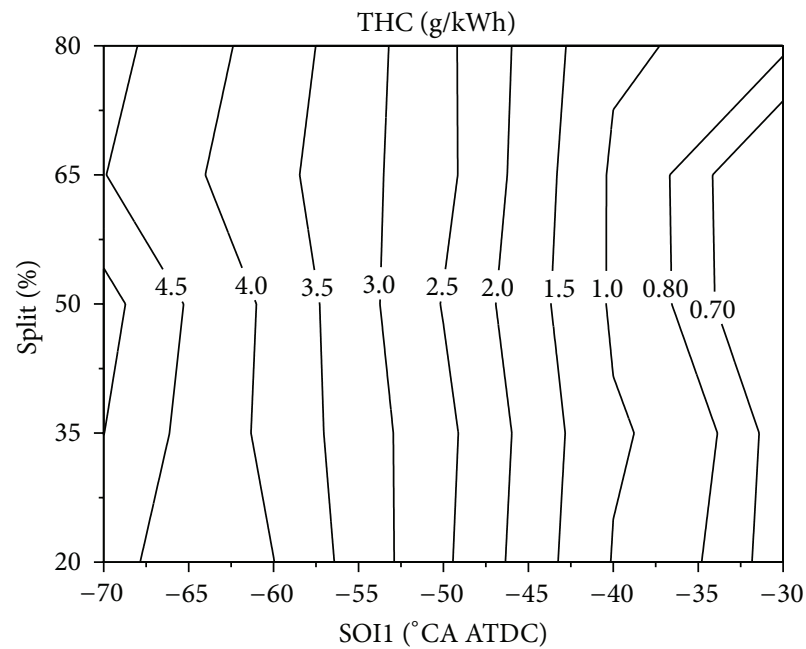

(d) THC

FIGURE 9: Emissions as a function of SOI1 and split percentage.

As Figure 9(d) shows, THC emitted from the doubleinjection strategy depends monotonically upon SOI1 in general. By applying earlier split injection under the running condition previously described, the spray penetration is increased due to the lower in-cylinder gas densities early in the compression stroke, so the split fuel is likely to cause serious spray impingement on combustion chamber wall surface, or enters into the crevice volume. Thus, gasoline LTC with double-injection strategy produces more THC with earlier SOI1 mainly due to partial flame quenching near cylinder wall, or unburned $\mathrm{HC}$ remains in the crevice volume and then is released during the exhaust stroke consequently. Meanwhile, the distributions of CO and THC emissions fully illustrate the change of combustion efficiency with SOI1 and split percentage as well.

3.2. The High Load Performance for Single- and DoubleInjection Strategies. Based on the previous results, it was decided to investigate the capability of operating range expansion of the double-injection strategy, while the experiment performed with single-injection strategy had been added as a reference. Euro VI emission regulation and engine design were adequately considered to determine the criteria. The values of $\mathrm{NO}_{X}$ and soot emissions were both within the Euro VI regulation. The limits of MPRR and maximum cylinder pressure $\left(P_{\max }\right)$ were set to $1.2 \mathrm{MPa} /{ }^{\circ} \mathrm{CA}$ and $16 \mathrm{MPa}$, respectively, preventing mechanical damage to the test engine. In addition, the $\mathrm{COV}_{\text {IMEP }}$ of each test point should be less than $5 \%$ for stable combustion. During the experiments, the fuel mass was gradually increased until one or more of the following criteria were violated.

(i) $\mathrm{NO}_{X}<0.4 \mathrm{~g} / \mathrm{kWh}$;

(ii) soot $<0.01 \mathrm{~g} / \mathrm{kWh}$;

(iii) $\mathrm{MPRR}<1.2 \mathrm{MPa} /{ }^{\circ} \mathrm{CA}$;

(iv) $\mathrm{COV}_{\text {IMEP }}<5 \%$;

(v) $P_{\max }<16 \mathrm{MPa}$. 
TABlE 3: Parameters of maximum load for different injection strategies.

\begin{tabular}{|c|c|c|}
\hline Injection strategies & Double & Single \\
\hline SOI1 ( ${ }^{\circ} \mathrm{CA}$ ATDC) & -43 & - \\
\hline SOI2 ( ${ }^{\circ} \mathrm{CA}$ ATDC $)$ & -23.5 & -27.3 \\
\hline Split percentage & $30 \%$ & - \\
\hline CA50 ( ${ }^{\circ} \mathrm{CA}$ ATDC $)$ & 10 & 10 \\
\hline EGR & $45 \%$ & $45 \%$ \\
\hline Injection pressure $(\mathrm{MPa})$ & 50 & 50 \\
\hline Indicated thermal efficiency & $44.1 \%$ & $44.6 \%$ \\
\hline Combustion efficiency & $97.3 \%$ & $98.4 \%$ \\
\hline $\operatorname{IMEP}(\mathrm{MPa})$ & 1.204 & 1.11 \\
\hline $\operatorname{MPRR}\left(\mathrm{MPa} /{ }^{\circ} \mathrm{CA}\right)$ & 1.23 & 1.18 \\
\hline$P_{\max }(\mathrm{MPa})$ & 12.84 & 12.66 \\
\hline $\mathrm{NO}_{X}(\mathrm{~g} / \mathrm{kWh})$ & 0.17 & 0.32 \\
\hline soot (g/kWh) & 0.98 & 0.76 \\
\hline $\mathrm{CO}(\mathrm{g} / \mathrm{kWh})$ & 1.80 & 1.10 \\
\hline THC (g/kWh) & 1.16 & 0.40 \\
\hline
\end{tabular}

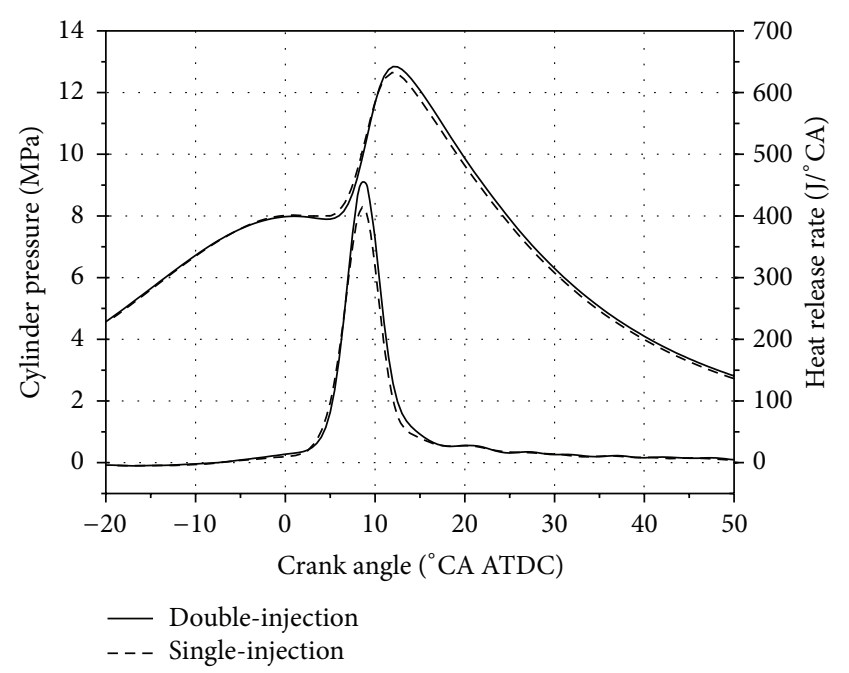

FIGURE 10: Cylinder pressure and heat release profiles of single- and double-injection strategies.

As mentioned in the previous section, the combination of advanced SOI1 and increased split percentage often generates unacceptable MPRR as well as soot deterioration. These two key factors had to be taken into account carefully during the load expansion, while maintaining relatively high combustion efficiency. Thus, the strategy with later SOI1 coupled with lower split percentage was applied for better comprehensive performance; the first injection was placed at $-43^{\circ} \mathrm{CA}$ ATDC with a split percentage of $30 \%$. During the process of operation range expansion, the combustion is configured to provide a CA50 of approximately $10^{\circ} \mathrm{CA}$ ATDC through adjusting injection timings. Further details of the test condition are documented in Table 3.

Figure 10 compares the cylinder pressure and heat release profiles of the single- and double-injection strategies. They both exhibit single-peak heat release pattern under the test condition. The original engine equipped with a selective catalytic reduction (SCR) exhaust catalyst is enough to approach Euro IV emission standard even at the full load with IMEP of 1.8 $\mathrm{MPa}$. In the effort of optimizing injection parameters, the maximum IMEP of gasoline LTC is extended from $1.11 \mathrm{MPa}$ to 1.204 MPa as figured in Table 3. This indicates that applying fuel double-injection strategy is totally feasible to extend operation range covering the low and medium load conditions commonly used, along with $\mathrm{NO}_{X}$ and soot levels below Euro VI emission standard without posttreatment system. But the combustion efficiency is slightly decreased because of split injection, and consequently the indicated thermal efficiency declines to some extent. Through the enhanced mixture stratification in the double-injection strategy, MPRR can be held within acceptable level and $P_{\max }$ is far below the engine design limit.

In the aspect of main emissions, $\mathrm{NO}_{X}$ emission of the double-injection strategy is further reduced by approximately $50 \%$ due to the leaner mixture from split fuel as compared to the single-injection case. It is suggested that $\mathrm{NO}_{X}$ emission could be well controlled by either the single- or doubleinjection strategy with sufficient boost and EGR. The fuel double-injection delivers slightly higher soot emission, which is mainly attributed to partial overlap between the second injection and combustion under the parameter settings. Furthermore, as shown clearly in Table 3 , the increase of IMEP is limited due to the violation of soot criteria rather than others with increasing total fuel mass. Therefore, similar to MPRR, soot emission is also turned out to be a major factor determining the operation range, and they are related in a trade-off relationship as discussed previously in the doubleinjection strategy of gasoline LTC. Not surprisingly, the double-injection strategy emits more $\mathrm{CO}$ and THC emissions than the single-injection strategy mainly due to the lower incylinder combustion temperature and flame quenching near cylinder wall, respectively. The penalty of CO and THC is supposed to be one of the major reasons for the decreased combustion efficiency and indicated thermal efficiency.

\section{Discussions}

Overall, due to the trade-off relationship between MPRR and soot emission, it is difficult to accomplish high-efficiency and clean combustion with pure gasoline over the whole operation range of the original engine. During the optimization study on fuel properties in LTC, researchers have pained much emphasis on bio-fuels, for example, alcohol fuels. Applying alcohol fuels with excessively high oxygen content, and free from aromatic hydrocarbon and sulfur, has been identified to be an effective pathway for solving the issue existing in the load expansion of gasoline LTC due to the remarkable effect of innate oxygen on soot reduction. Butanol, as a competitive alternative fuel, has several advantages over the conventional alcohol alternative fuels for the engine applications [17]. In the four butanol isomers, $\mathrm{n}$-butanol with the unique molecular structure and decomposition reaction shows the least potential to produce polycyclic aromatic hydrocarbons (PAHs), which is usually 
considered to be the soot precursor [18]. Therefore, superior engine performance and emissions can be attained using either neat n-butanol $[19,20]$ or its blend with conventional fossil fuels [21]. However, how to achieve well-organized combustion with n-butanol needs much more studies in the future.

\section{Conclusions}

In the present work, experimental study has been conducted to investigate the effect of fuel injection strategies on the engine performance, emissions, and load expansion capability on a single-cylinder CI engine. The conclusions that can be withdrawn from this paper are as follows.

(1) With the fixed CA50, the peak HRR is reduced by advancing SOI1 and increasing split percentage.

(2) Higher indicated thermal efficiency, as well as lower MPRR and $\mathrm{COV}_{\text {IMEP }}$, can be achieved simultaneously with later SOI1 and higher split percentage.

(3) As split percentage increases, $\mathrm{NO}_{X}$ emission decreases but soot emission increases. $\mathrm{CO}$ and THC emissions are increased by advancing SOI1, resulting in a slight decrease in combustion efficiency.

(4) Compared with the single-injection strategy, the double-injection strategy enables successful expansion of high-efficiency and clean combustion region, covering the commonly used engine loads. But soot, CO, and THC emissions are increased with the double-injection strategy at high loads, slightly declining the combustion efficiency and indicated thermal efficiency.

(5) MPRR and soot emission are thought to be the predominant constraints to the load expansion of gasoline LTC, while they are related to their trade-off relationship.

\section{Nomenclature}

ATDC: After top dead center

CA: Crank angle

CA50: The combustion phase of $50 \%$ accumulative heat release

CI: Compression ignition

CO: Carbon monoxide

$\mathrm{CO}_{2}$ : Carbon dioxide

COV: Coefficient of variability

EGR: Exhaust gas recirculation

FSN: Filter smoke meter

$\mathrm{H}_{2}$ : Hydrogen

HCCI: Homogenous charge compression ignition

HRR: Heat release rate

IMEP: Indicated mean effective pressure

LHV: Lower heating value

LTC: Low temperature combustion

MPRR: Maximum pressure rise rate

$\mathrm{NO}_{X}$ : Nitrogen oxides

PAHs: Polycyclic aromatic hydrocarbons
PCCI: Premixed charge compression ignition

PM: Particle matter

PPC: Partially premixed combustion

RON: Research octane number

rpm: Revolutions per minute

SCR: Selective catalytic reduction

SOC: Start of the combustion

SOI1: Start of the first injection

SOI2: Start of the second injection

THC: Total hydrocarbon.

\section{Conflict of Interests}

The authors declare that there is no conflict of interests regarding the publication of this paper.

\section{Acknowledgments}

The research is sponsored by Natural Science Foundation of China through the project of Outstanding Young Scholarship Award (Grant no. 51125026) and Natural Science Foundation of China through its project (Grant no. 51176140).

\section{References}

[1] M. Yao, Z. Zheng, and H. Liu, "Progress and recent trends in homogeneous charge compression ignition (HCCI) engines," Progress in Energy and Combustion Science, vol. 35, no. 5, pp. 398-437, 2009.

[2] W. L. Hardy and R. D. Reitz, "A study of the effects of high EGR, high equivalence ratio, and mixing time on emissions levels in a heavy-duty diesel engine for PCCI combustion," SAE Paper 2006-01-0026, 2006.

[3] M. Alriksson, T. Rente, and I. Denbratt, "Low soot, low $\mathrm{NO}_{X}$ in a heavy duty diesel engine using high levels of EGR," SAE Paper 2005-01-3836, 2005.

[4] S. Kook, C. Bae, P. C. Miles, D. Choi, and L. M. Pickett, "The influence of charge dilution and injection timing on lowtemperature diesel combustion and emissions," SAE Paper 2005-01-3837, 2005.

[5] D. Turner, G. Tian, and H. Xu, "An experimental study of dieseline combustion in a direct injection engine," SAE Paper 2009-01-1101, 2009.

[6] A. Weall and N. Collings, "Investigation into partially premixed combustion in a light-duty multi-cylinder diesel engine fuelled with a mixture of gasoline and diesel," SAE Paper 2007-01-4058, 2007.

[7] B. Johansson, "High-load partially premixed combustion in a heavy-duty diesel engine," in Proceedings of the Directions in Engine Efficiency and Emissions Research Conference (DEER '05), 2005.

[8] V. Manente, B. Johansson, and W. Cannella, "Gasoline partially premixed combustion, the future of internal combustion engines?" International Journal of Engine Research, vol. 12, no. 3, pp. 194-208, 2011.

[9] L. Hildingsson, G. Kalghatgi, N. Tait, B. Johansson, and A. Harrison, "Fuel octane effects in the partially premixed combustion regime in compression ignition engines," SAE Paper 2009-012648, 2009. 
[10] G. T. Kalghatgi, P. Risberg, and H.-E. Ångström, "Partially pre-mixed auto-ignition of gasoline to attain low smoke and low NOX at high load in a compression ignition engine and comparison with a diesel fuel," SAE Paper 2007-01-0006, 2007.

[11] R. Hanson, D. Splitter, and R. Reitz, "Operating a heavy-duty direct-injection compression-ignition engine with gasoline for low emissions," SAE Paper 2009-01-1442, 2009.

[12] S. Ciatti and S. N. Subramanian, "An experimental investigation of low-octane gasoline in diesel engines," Journal of Engineering for Gas Turbines and Power, vol. 133, no. 9, Article ID 092802, 2011.

[13] H. Yang, S. Shuai, Z. Wang, and J. Wang, "Fuel octane effects on gasoline multiple premixed compression ignition (MPCI) mode," Fuel, vol. 103, pp. 373-379, 2013.

[14] J. B. Heywood, Internal Combustion Engine Fundamentals, McGraw-Hill, New York, NY, USA, 1988.

[15] Afton Chemical Corporation, HiTEC 4140 Performance Additive, 2009.

[16] W. D. Ojeda, P. Zoldak, R. Espinosa, and R. Kumar, "Development of a fuel injection strategy for partially premixed compression ignition combustion," SAE Paper 2009-01-1527, 2009.

[17] C. Jin, M. Yao, H. Liu, C.-F. F. Lee, and J. Ji, "Progress in the production and application of n-butanol as a biofuel," Renewable and Sustainable Energy Reviews, vol. 15, no. 8, pp. 40804106, 2011.

[18] H. Jin, Y. Wang, K. Zhang, H. Guo, and F. Qi, "An experimental study on the formation of polycyclic aromatic hydrocarbons in laminar coflow non-premixed methane/air flames doped with four isomeric butanols," Proceedings of the Combustion Institute, vol. 34, no. 1, pp. 779-786, 2013.

[19] X. Han, M. Zheng, and J. Wang, "Fuel suitability for low temperature combustion in compression ignition engines," Fuel, vol. 109, pp. 336-349, 2013.

[20] M. Zheng, T. Li, and X. Han, "Direct injection of neat n-butanol for enabling clean low temperature combustion in a modern diesel engine," Fuel, vol. 142, pp. 28-37, 2015.

[21] B. Yang, M. Yao, W. K. Cheng, Z. Zheng, and L. Yue, "Regulated and unregulated emissions from a compression ignition engine under low temperature combustion fuelled with gasoline and n-butanol/gasoline blends," Fuel, vol. 120, pp. 163-170, 2014. 

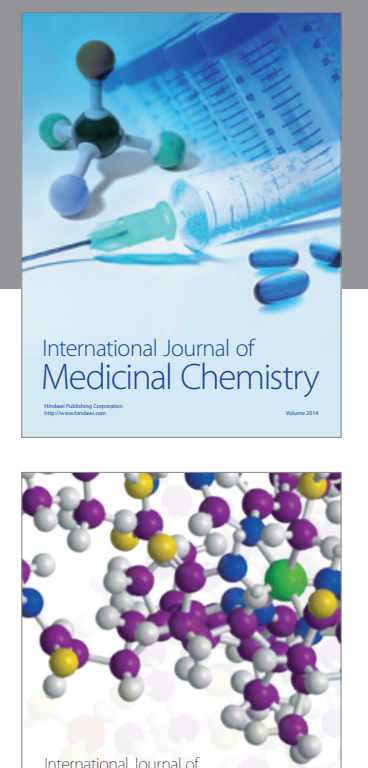

\section{Carbohydrate} Chemistry

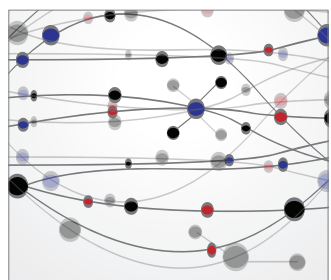

The Scientific World Journal
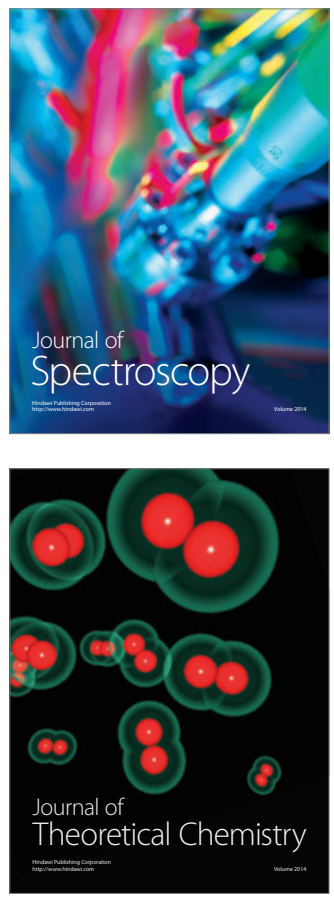
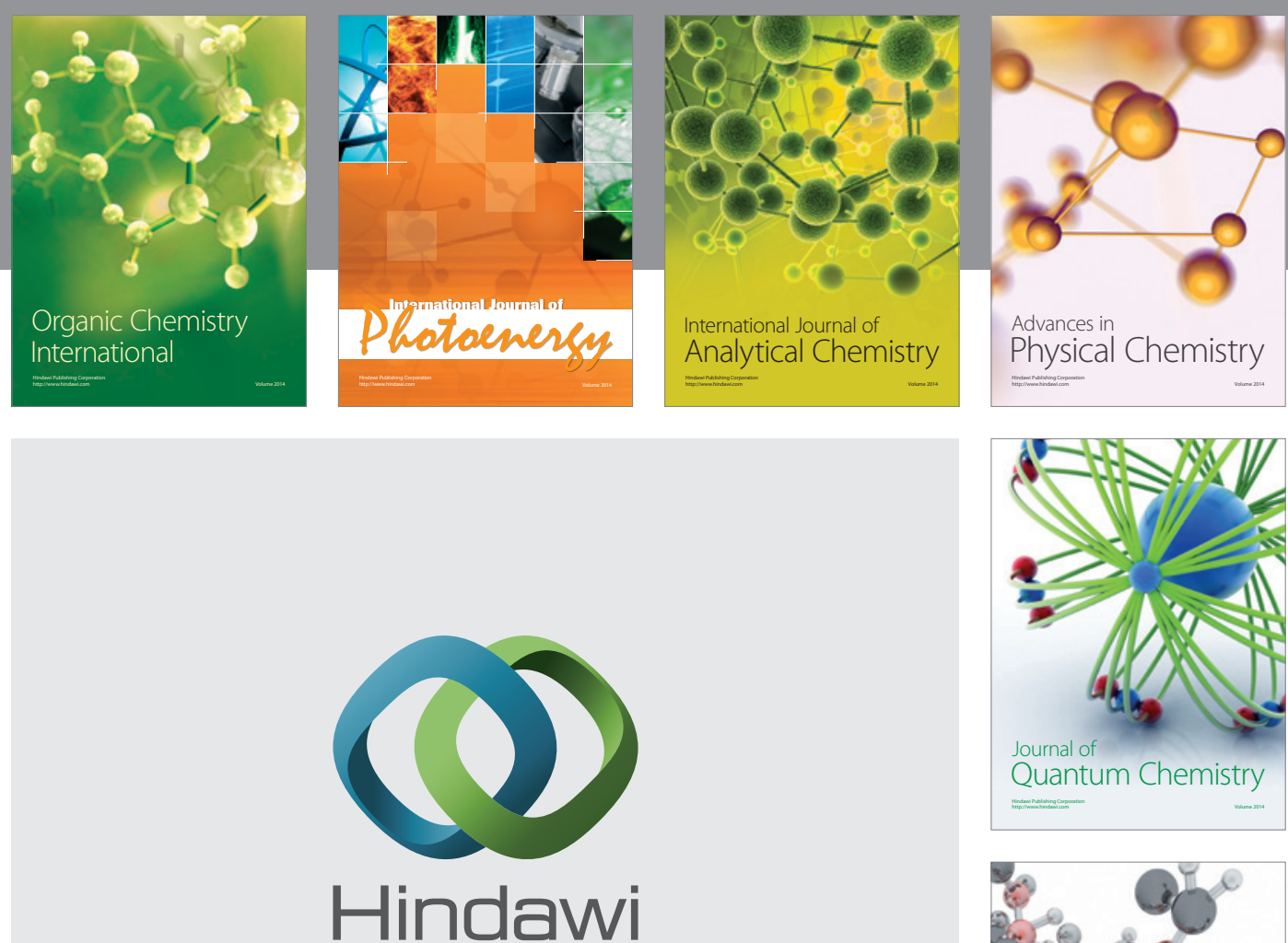

Submit your manuscripts at

http://www.hindawi.com

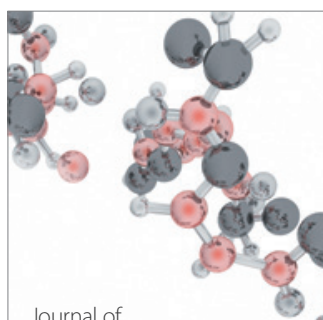

Analytical Methods

in Chemistry

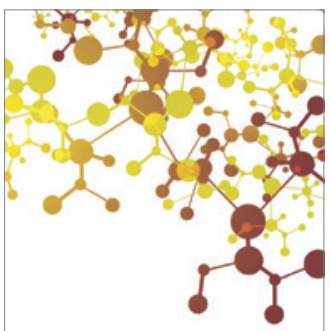

Journal of

Applied Chemistry

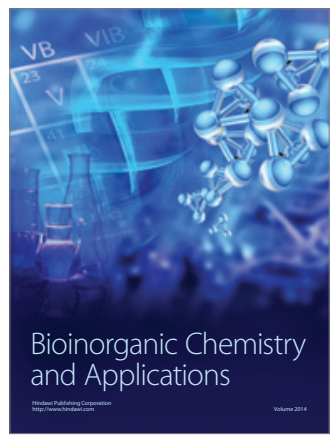

Inorganic Chemistry
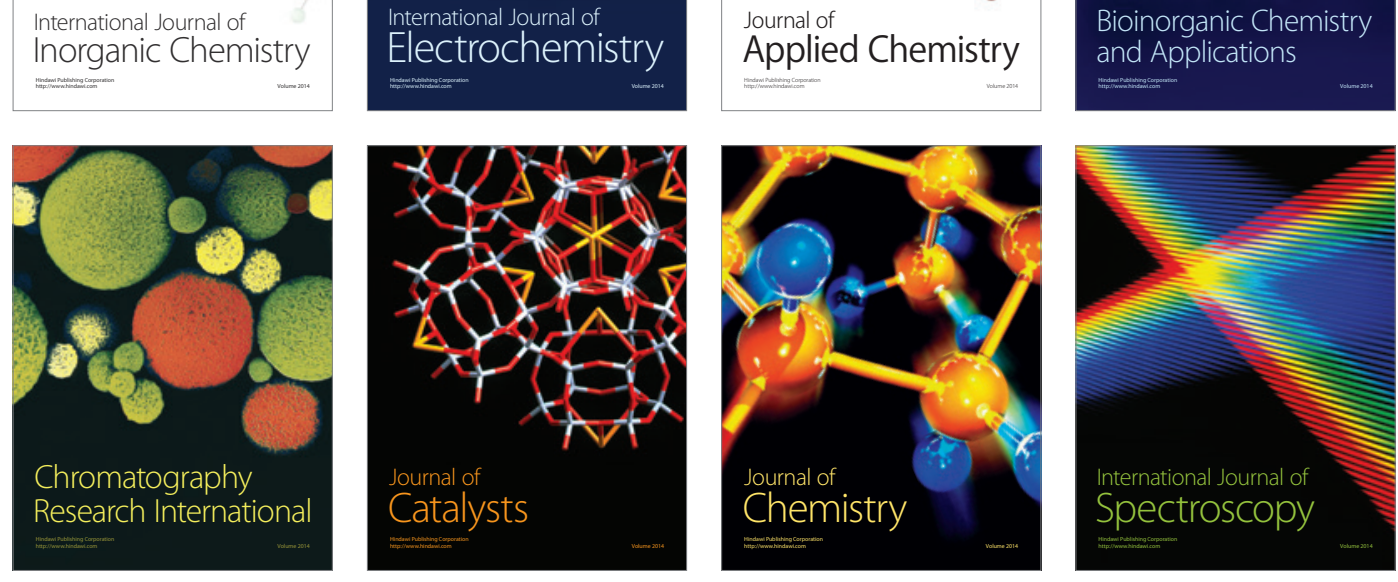